\title{
POLA RUANG DAN STRATEGI PEMANFAATAN LAHAN BUDIDAYA DI PERAIRAN TELUK KOTANIA, KABUPATEN SERAM BAGIAN BARAT, PROVINSI MALUKU
}

\author{
(Spatial Patterns and Cultivated Land Utilization Strategy in Kotania Bay, \\ West Seram Regency, Maluku Province)
}

\author{
Saifuddin Koto $^{1 *}$, Alex S. W. Retraubun ${ }^{2}$, Dicky Sahetapy ${ }^{2}$ \\ ${ }^{1)}$ Mahasiswa Program Studi Magister Ilmu Kelautan Pascasarjana Universitas Pattimura \\ 2) Jurusan Manajemen Sumberdaya Perairan Fakultas Perikanan dan Ilmu Kelautan Universitas Pattimura \\ *ipulkoto56@gmail.com,alexretraubun@yahoo.com,dicky_sahetapy@yahoo.com \\ Corresponding author*
}

\begin{abstract}
ABSTRAK: Teluk Kotania Kabupaten Seram Bagian Barat dapat diklasifikasikan sebagai salah satu teluk yang unik karena memiliki lima pulau sangat kecil, serta memiliki potensi sumberdaya eksoistem pesisir penting. Teluk ini pun telah ditetapkan status sebagai Kawasan Konservasi Pesisir dan Pulau-Pulau Kecil (KKP3K). Penelitian ini bertujuan untuk 1) mengetahui potensi ruang sub-zona budidaya di Teluk Kotania, dan 2) menganalisis dan menformulasikan strategi pengelolaan budidaya laut di Teluk Kotania. Pengambilan data menggunakan metode wawancara dan observasi langsung di lapangan.Analisa data menggunakan indeks kesesuaian lahan untuk mengetahui potensi ruang budidaya (rumput laut, teripang, kepiting bakau dan ikan kerapu), sedangkan DPSIR digunakan untuk menghasilkan strategi pengelolaan budidaya laut di Teluk Kotania. Potensi wilayah budidaya laut di Teluk Kotania dibagi menjadi tiga sub zona budidaya dengan total luas 361,69 ha. Hasil penelitian menunjukkan kesesuaian lahan budidaya rumput laut diperoleh nilai S1 sebesar 66\% (237,43 ha) dan nilai S2 sebesar 34\% (124,26 ha). Kesesuaian lahan untuk budidaya teripang diperoleh nilai S1 sebesar 94\% (340,65 ha) dan nilai S2 sebesar 6\% (21,04 ha). Kesesuaian lahan budidaya yang diperuntukkan untuk kepiting bakau terutama spesies Scylla serrata diperoleh nilai sangat sesuai hingga $100 \%$. Kegiatan budidaya untuk ikan kerapu diperoleh nilai S1 sebesar 93\% (338,06 ha), sedangkan untuk nilai S2 sebesar $7 \%$ (23,63 ha).Terdapat 11 strategi yang direkomendasikan untuk pengelolan serta pengembangan kegiatan budidaya laut di Teluk Kotania.
\end{abstract}

Kata Kunci: Budidaya, indeks kesesuaian, rumput laut, teripang, teluk kotania

ABSTRACT: Kotania Bay, West Seram Regency can be clarified as one of the unique bays because it has five smallest islands, which has the important potential coastal ecosystem resources. This bay's status also has been assigned as a Coastal Conservation Area and Small Islands. These purposes of this research are 1) to know the sub-zone potential cultivation in Kotania Bay, and 2) to analyze and formulate the marine cultivation management strategy in Kotania Bay. The method of data collection used by the researcher are interviews and direct field observations. The data analysis used land suitability index to determine the potential cultivation space (seaweed, sea cucumbers, mangrove crabs and groupers), while the DPSIR is used to produce the marine culture management strategy in Kotania Bay. The potential marine cultivation in Kotania Bay is divided into three subzones cultivation with the total area 361,69 ha. The result of the research showed that the suitability of seaweed cultivation land obtained an S1 value of 66\% (237.43 ha) and an S2 
value of $34 \%$ ( 124.26 ha). The land suitability of the sea cucumber cultivation obtained an S1 value of 94\% (340.65 ha) and an S2 value of 6\% (21.04 ha). The suitability of cultivated land designated for mangrove crabs, especially the species of Scylla serrata, was obtained very suitable values up to $100 \%$. The cultivation activity for grouper fish obtained an S1 value of 93\% (338.06 ha), while for an S2 value of 7\% (23.63 ha). There are 11 recommended strategies for the management and development of marine cultivation activities in Kotania Bay.

Keywords: Aquaculture, cultivated land, seaweed, sea cucumber, Kotania Bay

\section{PENDAHULUAN}

Tingginya permintaan sumberdaya laut seperti ikan dan udang berdampak pada tingginya produksi sumberdaya laut untuk pemenuhan permintaan. Selain kegiatan perikanan penangkapan, perikanan budidaya merupakan kegiatan yang memproduksi biota atau organisme air untuk mendapatkan keuntungan (Setyono, 2004; Worang, dkk., 2018). Dalam aktivitas budidaya tentunya memerlukan suatu ruang agar terjadi keseimbangan antara kegiatan yang dilakukan dengan lingkungan. Penataan ruang merupakan suatu upaya untuk mengatur berbagai aktivitas yang terjadi di dalam ruang tersebut sehingga tidak menimbulkan konflik (Maesaroh, $d k k$, 2013).

Teluk Kotania merupakan salah satu teluk yang berada di wilayah perairan Kabupaten Seram Bagian Barat, dengan luas perairan $470.999 \mathrm{~km}^{2}$ dan kedalaman 0-200 $\mathrm{m}$. Teluk Kotania merupakan wilayah perairan semi tertutup dan memiliki potensi sumberdaya pesisir penting yaitu ekosistem mangrove, lamun dan terumbu karang. Pada ekosistem tersebut terdapat keanekaragaman sumberdaya hayati laut yang kaya seperti, ikan, moluska, ekinodermata, krustasea dan makro-algae yang bernilai ekonomis dan non-ekonomis (Nanlohy, 2014; Huliselan, $d k k, 2017)$. Seperti diketahui bahwa kegiatan budidaya rumput laut di Teluk Kotania pernah dilakukan tahun 2003-2011, namun rumput laut terkena penyakit yang disebabkan oleh faktor alam dan kualitas perairan yang tidak sesuai. Komoditas budidaya seperti ikan, rumput laut, udang memiliki nilai ekonomi yang tinggi secara nasional maupun internasional (Rarung\&Pratasik, 2010; Astusi \& Ariestyani, 2013; Oedjoe, $d k k$., 2019). Hal ini memicu kegiatan budidaya dilakukan di daerahdaerah serta didukung dengan wilayah perairan yang sesuai.

Pemerintah Kabupaten Seram Bagian Barat dalam kebijakan pembangunan telah menempatkan komoditas budidaya laut sebagai komoditas unggulan untuk dikembangkan. Pengembangan ini dilakukan dengan pertimbangan luas wilayah potensial bagi pengembangan komoditas ini tersedia. Menurut BKPMD Maluku (2009), luas areal budidaya laut yang sudah dikembangkan di Seram Bagian Barat adalah 213,50 ha dari potensi lahan budidaya yang telah dimanfaatkan $2.354,00$ atau hanya 9\%. Permasalahan yang dihadapi di wilayah pesisir untuk berbagai kegiatan salah satunya kegiatan budidaya antara lain penataan ruang dan pengembangannya yang tidak memperhatikan daya dukung lingkungan (Suban, dkk., 2019) yang bertujuan untuk mengetahui kondisi dan kesesuaian lahan budidaya. Penelitian ini bertujuan untuk 1) mengetahui potensi ruang sub-zona budidaya di Teluk Kotania, dan 2) menganalisis dan menformulasikan strategi pengelolaan budidaya laut di Teluk Kotania.

\section{METODE PENELITIAN}

Penelitian ini berlangsung dari bulan Februari hingga Maret 2020, di Teluk Kotania Kabupaten Seram Bagian Barat, Maluku (Gambar 1). Lokasi pengambilan sampel tepatnya pada sub zona budidaya berdasarkan hasil penelitian Huliselan, $d k k$ (2018). Pengumpulan data primer dilakukan melalui wawancara dan observasi langsung di lapangan, sedangkan data sekunder diperoleh dari literatur berupa jurnal ilmiah serta informasi terkait 
lainnya. Kriteria kesesuaian lahan budidaya (rumput laut, teripang, kepiting bakau dan ikan kerapu) dinilai berdasarkan kisaran nilai indeks kesesuaian (Tabel 1-4). Data kesesuaian lahan budidaya dibedakan pada tingkat kelas sebagai berikut:

1. Kelas S1: Sangat Sesuai (Highly suitable), yaitu jika lahan atau kawasan sangat sesuai untuk budidaya tanpa ada faktor pembatas yang berarti. Parameter-parameter fisika, kimia dan biologi perairan memenuhi persyaratan atau ketentuan yang ideal. Faktor pembatas yang dimiliki bersifat minor dan tidak menurunkan produktivitasnya secara nyata pada kegiatan atau produksi hasil.

2. Kelas S2: Sesuai Bersyarat (Moderately Suitable), yaitu jika lahan mempunyai pembatas yang serius/agak besar yang berpengaruh mengurangi aktivitas/produktivitas produk budidaya dan keuntungan serta meningkatkan masukkan yang diperlukan. Parameter-parameter fisika, kimia dan biologi perairan sedikit memenuhi persyaratan/ketentuan yang ideal. Dalam pengelolaannya diperlukan tambahan input teknologi dan tingkat perlakuan.

3. Kelas 3-N: Tidak Sesuai (Not Suitable), yaitu lahan atau kawasan tidak sesuai diusahakan untuk kegiatan budidaya yang lestari karena memiliki faktor pembatas yang berat dan bersifat permanen. Parameter fisika, kimia dan biologi perairan tidak memenuhi persyaratan/ketentuan yang ideal.

Metode yang dipakai untuk analisa strategi pengelolaan budidaya menggunakan DPSIR, dengan menguraikan driving force (faktor penyebab), pressure (faktor pendorong yang mempercepat perubahan kondisi suatu keadaan), states (kondisi awal), impact (dampak perubahan itu), dan responses (respon stakeholder/subjek terkait pada perubahan itu).

\section{HASIL DAN PEMBAHASAN}

\section{Potensi Lahan Budidaya Laut}

Potensi wilayah budidaya laut di Teluk Kotania dibagi menjadi tiga sub zona budidaya dengan total luas 361,69 ha (Huliselan, $d k k$., 2018):

1. Sub zona budidaya laut 1 dengan luasan 32,65 ha difokuskan untuk budidaya ikan beronang (Siganus canaliculatus, S. lineatus dan S. guttatus) yang bernilai ekonomis Pada area mangrove difokuskan untuk budidaya kepiting bakau (Scylla serrata).

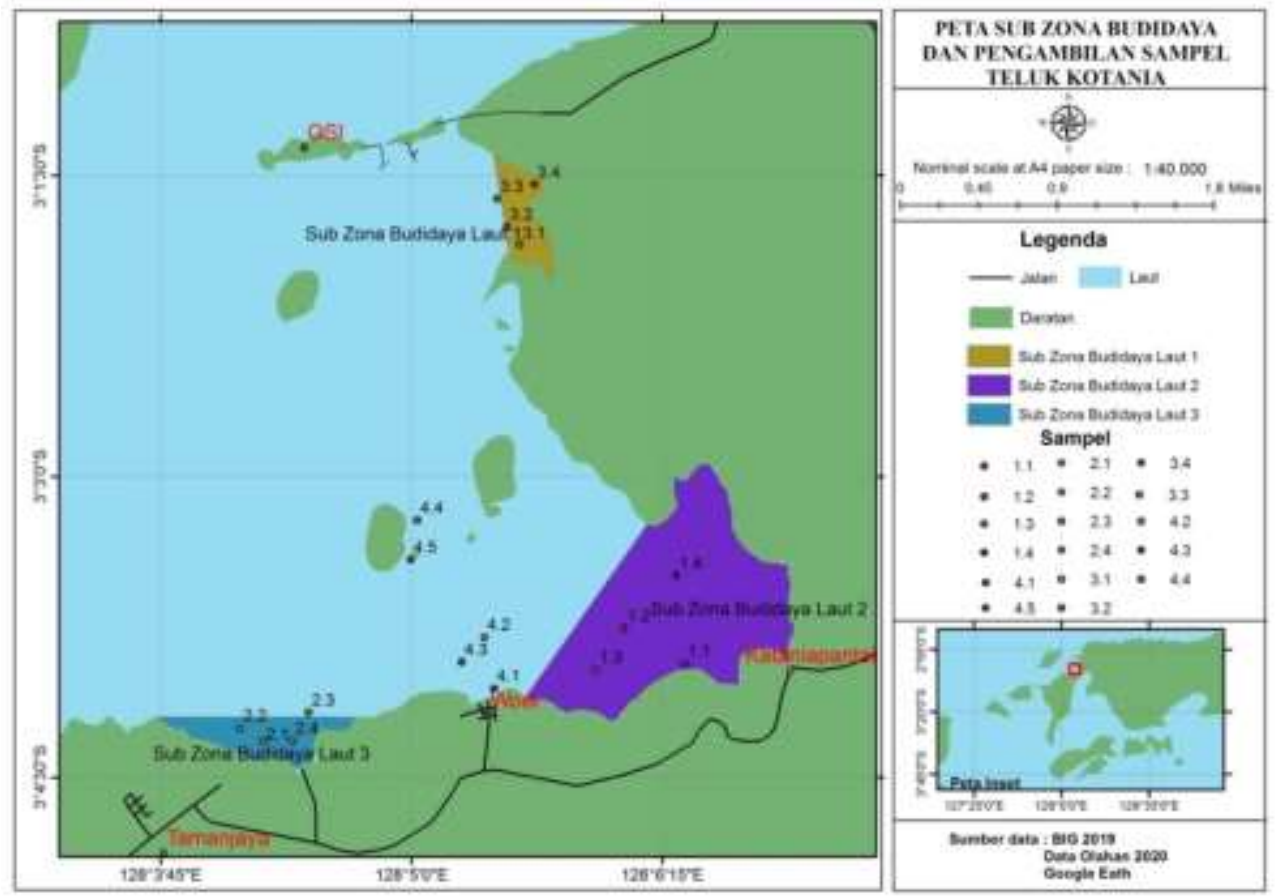

Gambar 1. Peta lokasi penelitian 
DOI: https://doi.org/10.30598/TRITONvol16issue1page28-37

Tabel 1. Kriteria kesesuaian lahan budidaya rumput laut

\begin{tabular}{clclll}
\hline No & \multicolumn{1}{c}{ Kriteria } & $\begin{array}{c}\text { Nilai } \\
\text { bobot }\end{array}$ & $\begin{array}{c}\text { Di bawah baku } \\
\text { mutu (N) }\end{array}$ & $\begin{array}{c}\text { Kisaran } \\
\text { Toleransi (S1) }\end{array}$ & \multicolumn{1}{c}{$\begin{array}{c}\text { Kisaran } \\
\text { Optimal (S2) }\end{array}$} \\
\hline 1 & Tinggi Gelombag (m) & 1 & $>1$ & $0-0.025$ & $0.26-0.5$ \\
2 & Kec. Arus (cm/det) & 3 & $0-9$ atau $>50$ & $20-40$ & $10-19 / 41-50$ \\
3 & Kecerahan (m) & 2 & $<2$ & $>5$ & $<5-3$ \\
4 & Suhu $\left({ }^{0} \mathrm{C}\right)$ & 2 & $<25$ atau $>32$ & $27-30$ & $25-<27$ atau $>30-32$ \\
5 & pH & 3 & $<6.5$ atau $>9.5$ & $7-8.5$ & $6.5-<7$ atau $8.5-9.5$ \\
6 & Salinitas (o/oo) & 2 & $<25$ atau $>37$ & $29-33$ & $25-<29$ atau $>33-37$ \\
7 & DO (mg/l) & 2 & $<2$ & $>4$ & $2-4$ \\
8 & Nitrat (mg/l) & 3 & $<0.01$ & $0.1-0.7$ & $0.01-<0,1$ \\
9 & Fosfat (mg/l) & 3 & $<0.02$ & $0.1-0.2$ & $0.02-<0.1$ \\
\hline Sumber: & KepmenNo.51/MENKLH/2004, Arivati, $d k k$., $(2007)$ &
\end{tabular}

Tabel 2. Kriteria kesesuaian lahan budidaya teripang

\begin{tabular}{|c|c|c|c|c|c|}
\hline No & Kriteria & $\begin{array}{c}\text { Nilai } \\
\text { bobot }\end{array}$ & $\begin{array}{c}\text { Di bawah baku } \\
\text { mutu }(\mathbf{N})\end{array}$ & $\begin{array}{c}\text { Kisaran } \\
\text { Toleransi (S1 ) }\end{array}$ & $\begin{array}{c}\text { Kisaran } \\
\text { Optimal (S2) }\end{array}$ \\
\hline 1 & Kedalaman (m) & 1 & $>20$ & $15-20$ & $<15$ \\
\hline 2 & Arus $(\mathrm{cm} / \mathrm{dt})$ & 1 & $<10$ atau >41 & $20-30$ & $11-20$ atau $31-40$ \\
\hline 3 & Suhu $\left({ }^{\circ} \mathrm{C}\right)$ & 2 & $<23$ atau $>34$ & $23-<27$ & $28-<32$ \\
\hline 4 & Salinitas (\%o) & 2 & $<26$ atau $>36$ & $34-36$ & $26-33$ \\
\hline 5 & $\mathrm{pH}$ & 2 & $<6,5$ atau $>8,5$ & $6,5-7,9$ & $>7,9-8,4$ \\
\hline 6 & Oksigen terlarut $(\mathrm{mg} / \mathrm{l})$ & 3 & $<4$ & $4-9$ & $>9$ \\
\hline imber: & $\begin{array}{l}\text { Sulardiono, } d k k .,(2017) \\
\text { Nilai Evaluasi Kelayakan Te }\end{array}$ & & . & $55-91,66$ & \\
\hline
\end{tabular}

Tabel 3. Kriteria kesesuaian lahan budidaya kepiting bakau

\begin{tabular}{|c|c|c|c|c|c|}
\hline No & Kriteria & $\begin{array}{l}\text { Nilai } \\
\text { bobot }\end{array}$ & $\begin{array}{c}\text { Kisaran } \\
\text { Toleransi (S1) }\end{array}$ & $\begin{array}{c}\text { Kisaran } \\
\text { Optimal (S2) }\end{array}$ & $\begin{array}{l}\text { Dibawah baku } \\
\text { mutu (N) }\end{array}$ \\
\hline 1 & Tekstur tanah & 3 & Halus & Sedang & Kasar \\
\hline 2 & Jenis tanah & 3 & Aluvial & $\begin{array}{l}\text { Mediteran, } \\
\text { latosol }\end{array}$ & Grumosol \\
\hline 3 & Topografi & 2 & Datar & Berombak & Berbukit \\
\hline 4 & Kemiringan lahan (\%) & 2 & $0-2$ & $>2-8$ & $>8$ \\
\hline 5 & Penggunaan lahan & 2 & $\begin{array}{l}\text { Semak, } \\
\text { alang-alang, } \\
\text { rawa, tambak }\end{array}$ & $\begin{array}{l}\text { Pengembangan } \\
\text { pelabuhan, } \\
\text { kebun campuran }\end{array}$ & $\begin{array}{l}\text { Pemukiman, } \\
\text { hutan lindung }\end{array}$ \\
\hline 6 & Jarak dari sungai (m) & 1 & $<500$ & $500-2000$ & $>2000$ \\
\hline 7 & Jarak dari laut (m) & 1 & $<2000$ & $2000-4000$ & $>4000$ \\
\hline 8 & Jenis vegetasi pesisir & 3 & Mangrove & Nipah, nipah \& kelapa & Hutan \\
\hline 9 & Salinitas (ppt) & 3 & $15-25$ & $25-30$ & $<15$ \\
\hline
\end{tabular}

2. Sub zona budidaya laut 2 dengan luasan 282,91 ha difokuskan untuk budidaya ikan kerapu, beronang dan ikan kwee (Caranx sexfasciatus). Pada area mangrove diarahkan untuk budidaya kepiting bakau (Scylla serrata).
3. Sub zona budidaya laut 3 dengan luasan 46,13 ha difokuskan untuk budidaya ikan kerapu, beronang dan ikan kwee (Caranx sexfasciatus). Pada area mangrove diarahkan untuk budidaya kepiting bakau (Scylla serrata). 
Tabel 4. Kriteria kesesuaian lahan budidaya ikan kerapu

\begin{tabular}{|c|c|c|c|c|c|}
\hline No & Kriteria & $\begin{array}{c}\text { Nilai } \\
\text { Bobot }\end{array}$ & $\begin{array}{c}\text { Kisaran } \\
\text { Toleransi (S1 ) }\end{array}$ & $\begin{array}{c}\text { Kisaran } \\
\text { Optimal (S2) }\end{array}$ & $\begin{array}{l}\text { Di bawah baku } \\
\text { mutu (N) }\end{array}$ \\
\hline 1 & Ombak (m) & 3 & $0.01-0.09$ & $0.1-1.0$ & $>1$ \\
\hline 2 & Kedalaman (m) & 3 & $10-15$ & $16-20$ & $<10$ dan $>20$ \\
\hline 3 & Arus $(\mathrm{cm} / \mathrm{dt})$ & 2 & $5-10$ & $11-15$ & $<5$ dan $>15$ \\
\hline 4 & Kecerahan $(\%)$ & 2 & $80-100$ & $60-79$ & $<60$ \\
\hline 5 & Substrat dasar & 1 & $\begin{array}{l}\text { Pasir, sedikit lumpur, } \\
\text { rubbles }\end{array}$ & berlumpur & $\begin{array}{l}\text { pasir, berlumpur } \\
\text { banyak }\end{array}$ \\
\hline 6 & Salinitas (ppt) & 3 & $31-35$ & $25-30$ & $<25$ dan $>35$ \\
\hline 7 & $\mathrm{DO}(\mathrm{mg} / \mathrm{l})$ & 2 & $>6$ & $4-6$ & $<4$ \\
\hline 8 & Nitrat $(\mathrm{mg} / \mathrm{l})$ & 1 & $0.09-3,2$ & $0,7-0,8 ; 3,3-3,4$ & $<0,7 ;>3,4$ \\
\hline 9 & Fosfat $(\mathrm{mg} / \mathrm{l})$ & 1 & $0,2-0,5$ & $0,6-0,7$ & $<0,2 ;>0,7$ \\
\hline
\end{tabular}

Berdasarkan hasil analisa, parameter lingkungan perairan mencakup suhu, salinitas, $\mathrm{pH}$, dan beberapa faktor fisika-kimia lainnya, serta hasil kompilasi dari berbagai sumber sebagai data sekunder, diperoleh keadaan perairan dari ketiga sub zona budidaya laut menunjukkan tingkat kesesuaian budidaya laut sangat baik. Analisa kesesuaian lahan budidaya untuk rumput laut diperoleh nilai S1 (sangat sesuai) dengan luas lahan 237,43 ha (66\%), nilai S2 (sesuai bersyarat) dengan luas 124,26 ha (34\%), sedangkan nilai N (tidak sesuai) sebesar 0 ha $(0 \%)$ (Gambar 2). Kesesuaian lahan budidaya teripang diperoleh nilai S1 dengan luasan lahan sebesar 340,65 ha atau $94 \%$, nilai S2 dengan luas lahan sebesar 21,04 ha atau 6\% sedangkan $0 \%$ untuk nilai $\mathrm{N}$ (tidak sesuai) (Gambar 3). Kesesuaian lahan budidaya yang diperuntukkan untuk kepiting bakau terutama spesies Scylla serrata diperoleh sangat sesuai hingga 100\% (Gambar 4). Kegiatan budidaya untuk ikan kerapu diperoleh nilai kesesuaian lahan budidaya sebesar 338,06 ha atau 93\% yang sesuai, sedangkan untuk yang sesuai bersyarat diperoleh nilai $7 \%$ dengan luas lahan 23,63 ha (Gambar 5). Dengan demikian kawasan perairan Teluk Kotania memenuhi kriteria lahan yang cukup luas untuk pengembangan budidaya laut, sehingga mendapatkan jumlah produksi yang besar dengan mutu yang baik sesuai persyaratan tumbuh. Budidaya rumput laut, teripang, kepiting abkau serta ikan kerapu telah terbukti memiliki prospek yang menjanjikan (Soejarwo \& Fitriyanny, 2016; Ratna \& Suruwaky, 2016; Arthatiani, dkk., 2014; Shafitri \& Soejarwo, 2017).

\section{Strategi Pengelolaan Budidaya Laut}

Berdasarkan hasil analisa kesesuaian lahan budidaya diperoleh bahwa perairan di Teluk Kotania berpotensi untuk kegiatan budidaya serta pengembangannya. Produk budidaya rumput laut, teripang, kepiting bakau serta ikan kerapu memiliki nilai ekonomis yang tinggi sehingga dapat berdampak bagi peningkatan kesejahteraan masyarakat serta ekonomi daerah. Namun untuk melakukan kegiatan budidaya serta pengembangan ke depan maka diperlukan pengelolaan yang baik dan tepat sasaran (Adipu, $d k k$., 2013), sehingga manfaat yang diterima akan dirasakan bagi masyarakat dan daerah. Pengelolaan yang tepat memerlukan strategi yang tepat dengan melibatkan semua pihak terkait untuk menghasilkan keputusan yang tepat pula (Lesmana $d k k$, 2011). Hasil identifikasi DPSIR dan matriks keterkaitannya dapat dijelaskan sebagai berikut (Tabel 5 dan Tabel 6): 
Jurnal TRITON Volume 16, Nomor 1, April 2020, hal. $28-37$

P-ISSN 1693-6493 E-ISSN 2656-2758

33

DOI: https://doi.org/10.30598/TRITONvol16issue1page28-37

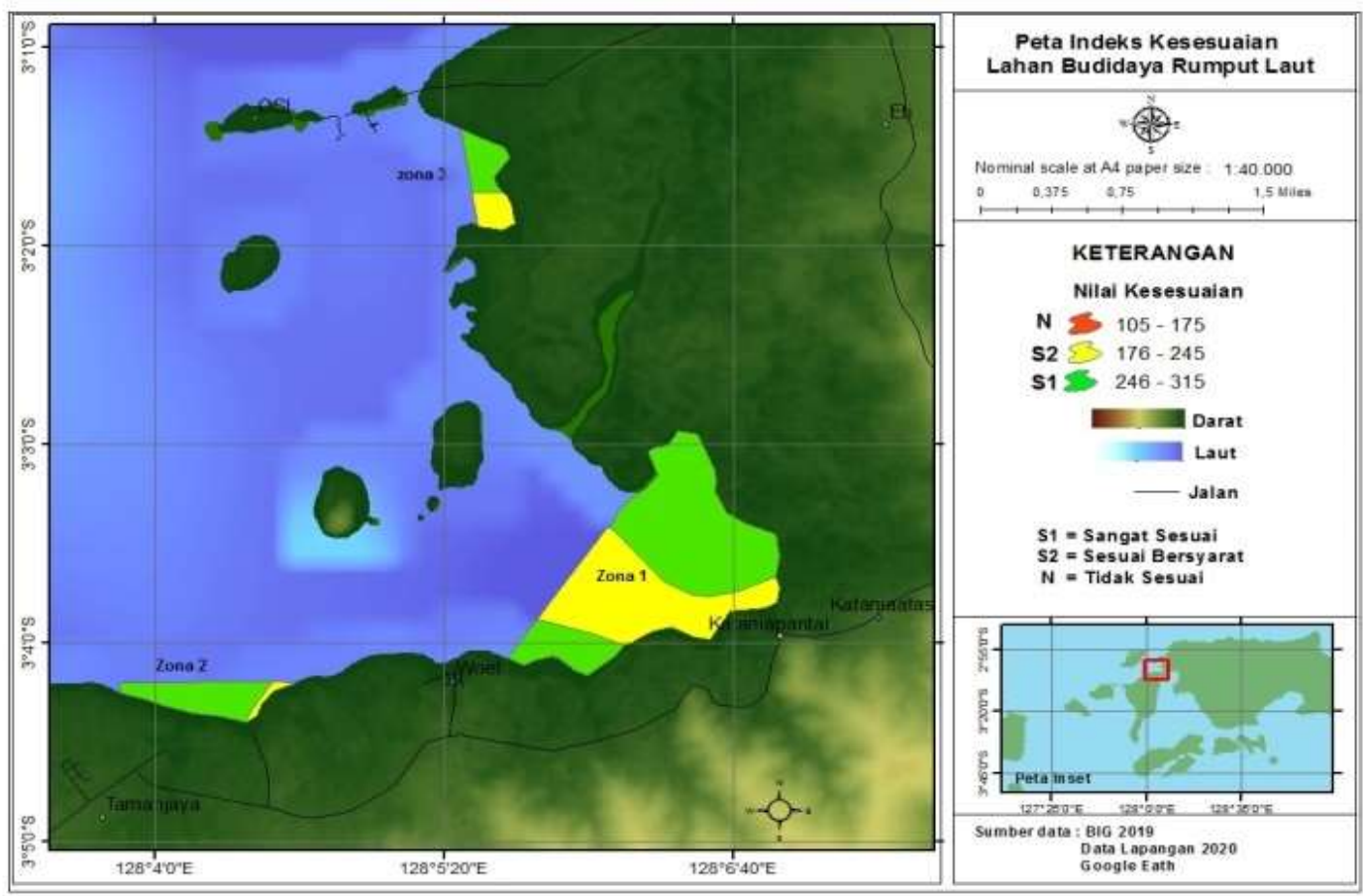

Gambar 2. Peta tematik kesesuaian lahan budidaya rumput laut
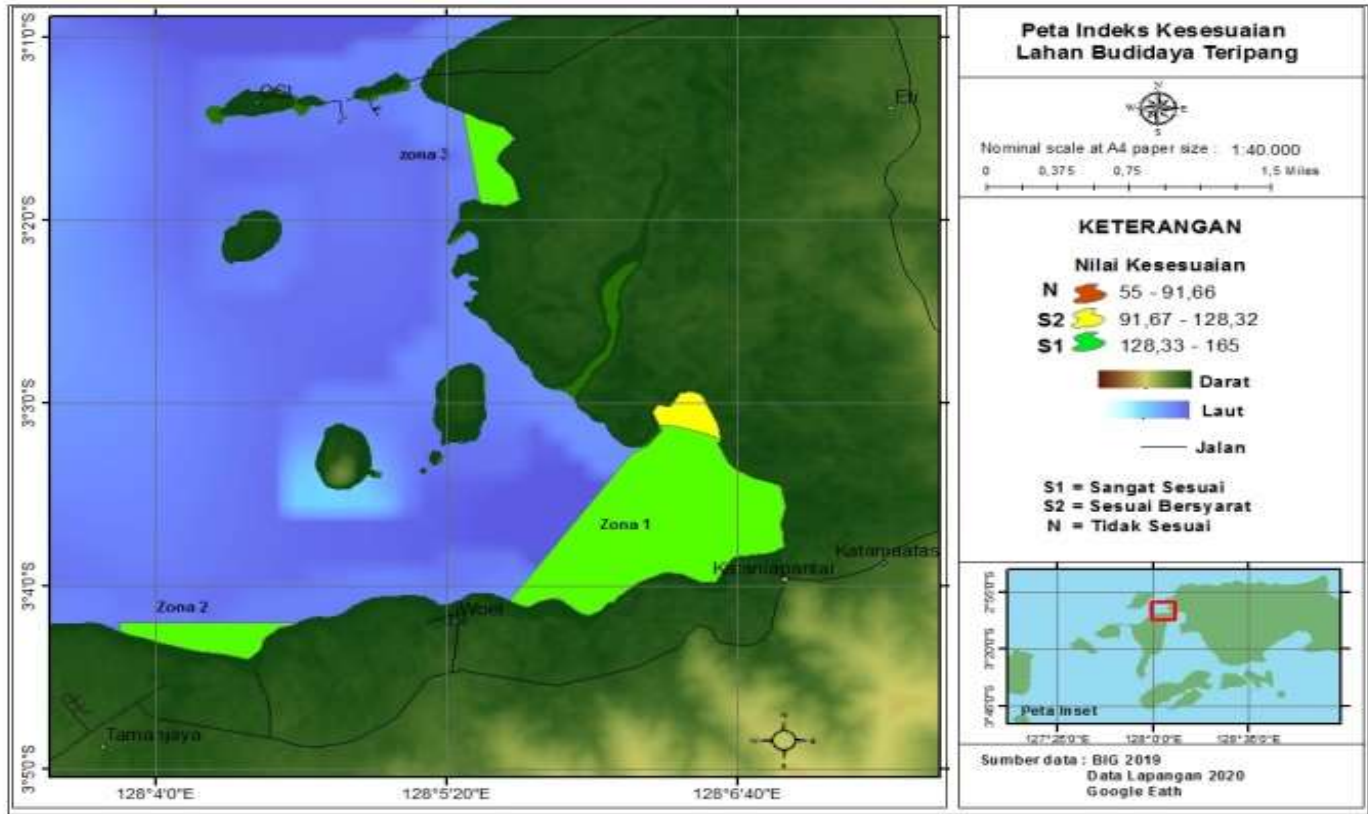

Gambar 3. Peta tematik kesesuaian lahan budidaya teripang 

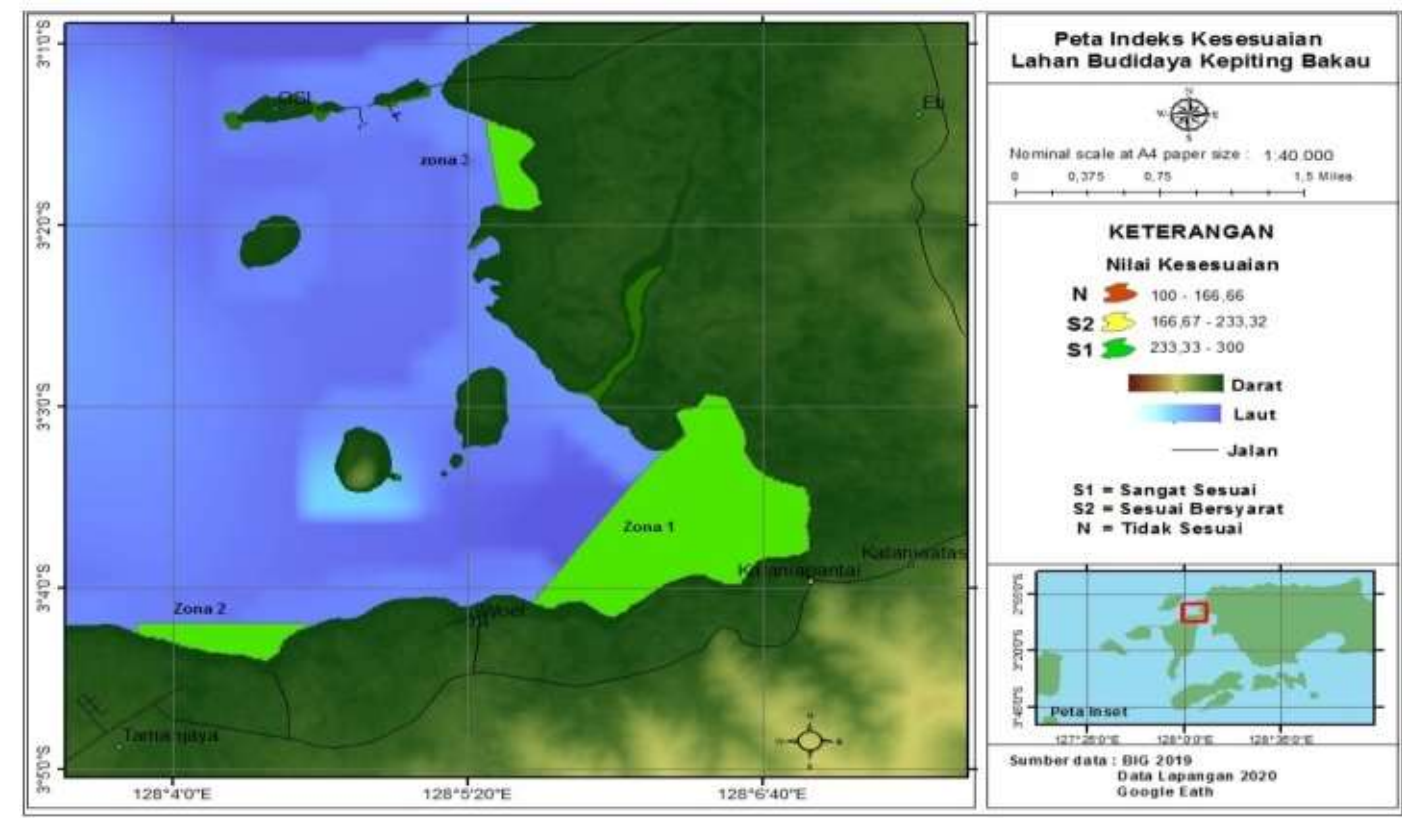

Gambar 4. Peta Tematik kesesuaian lahan budidaya kepiting bakau
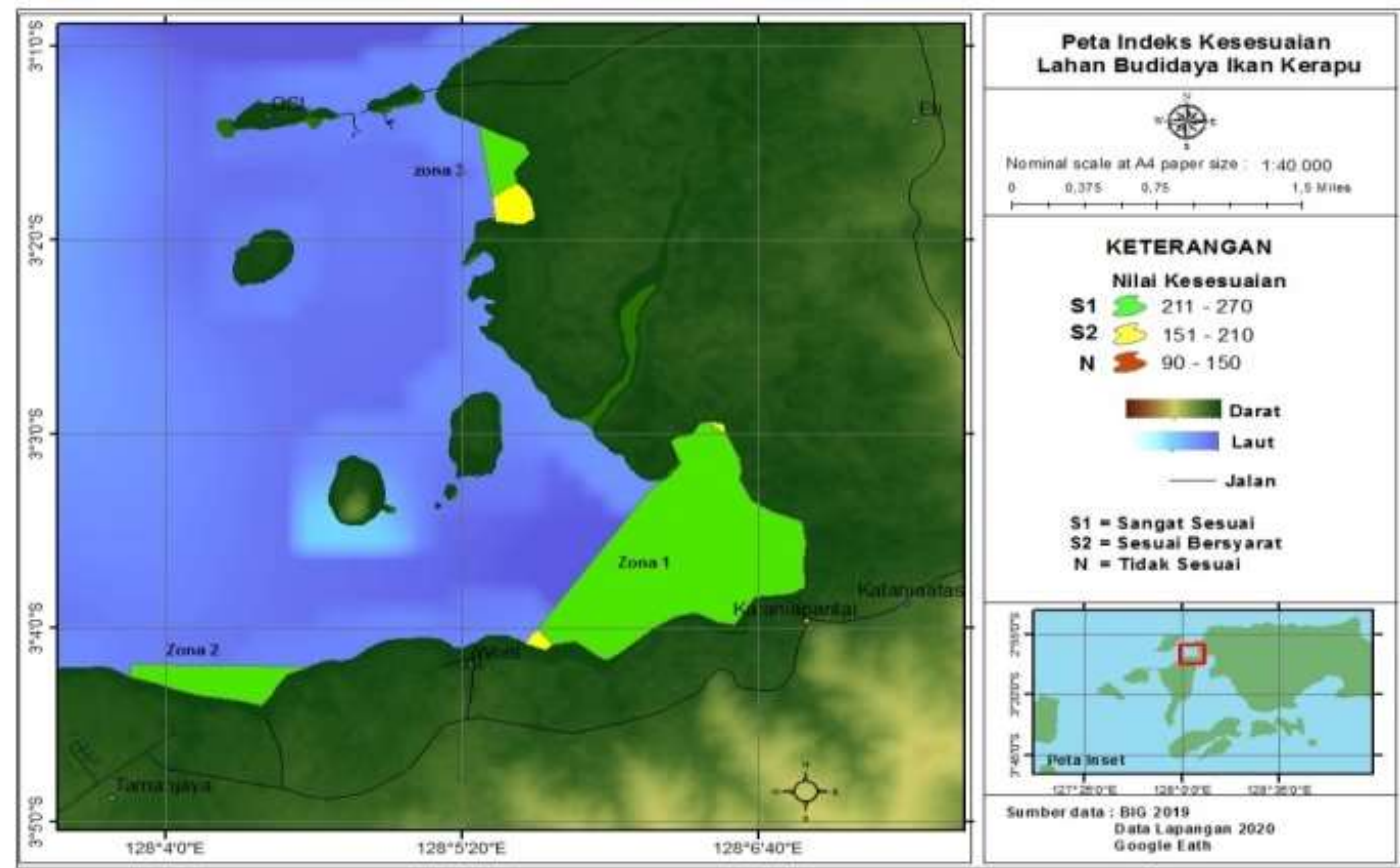

Gambar 5. Peta Tematik Kesesuaian Lahan Budidaya Ikan Kerapu 
Tabel 5. Matriks Komponen (DPSI)

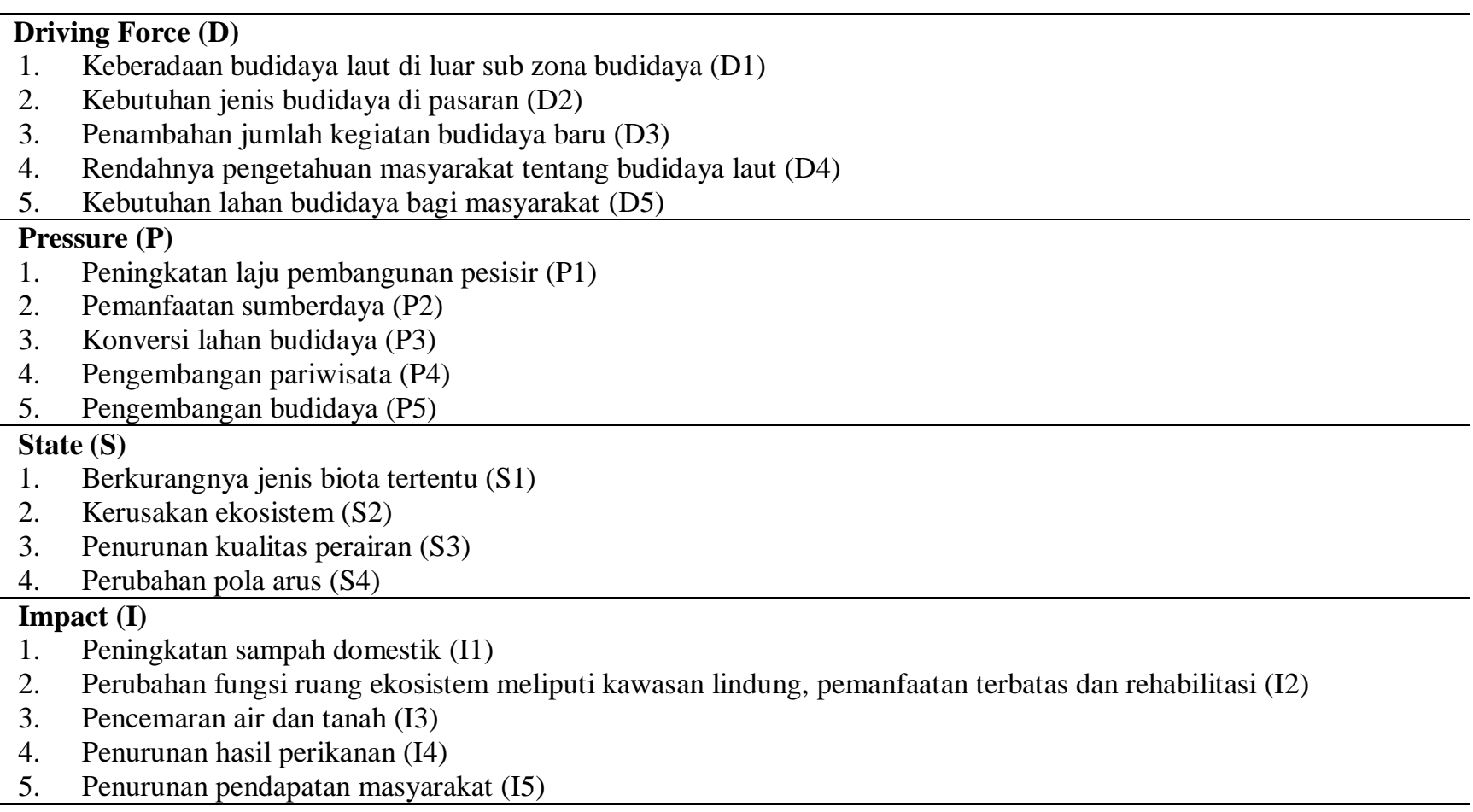

Tabel 3. Matriks keterkaitan komponen DPSIR dan skenario pengelolaan Teluk Kotania

\begin{tabular}{|c|c|c|}
\hline $\begin{array}{l}\text { Response Pada } \\
\text { Komponen DPSI }\end{array}$ & Skenario & Strategi Pengelolaan \\
\hline $\mathrm{R}-\mathrm{D}$ & Modify & $\begin{array}{l}\text { 1. Peningkatan partisipasi masyarakat yang proaktif dalam pengelolaan } \\
\text { budidaya laut, khususnya bagi golongan masyarakat yang berpengetahuan } \\
\text { luas seperti para pemuda (D1, D2, D3) } \\
\text { 2. Membuat workshop yang bertujuan memberi informasi dan pelatihan } \\
\text { kepada masyarakat di daerah tersebut (D4) } \\
\text { 3. Perencanaan budidaya laut berbasis daya dukung dan fungsi kawasan (D5) }\end{array}$ \\
\hline $\mathrm{R}-\mathrm{P}$ & Reduce & $\begin{array}{l}\text { 4. Mengatur dan menyelenggarakan peruntukan, penggunaan ruang melalui } \\
\text { penetapan zonasi didukung dengan zoning regulation }(\mathrm{P} 1, \mathrm{P} 2, \mathrm{P} 3, \mathrm{P} 4)\end{array}$ \\
\hline $\mathrm{R}-\mathrm{S}$ & Restore & $\begin{array}{l}\text { 5. Melakukan kerjasama dengan Dinas Perikanan dan Kelautan untuk } \\
\text { menyediakan bantuan teknis budidaya laut dan benih biota yang akan } \\
\text { dibudidaya (S1) } \\
\text { 6. Penataan ruang dengan memperhatikan integritas kawasan untuk fungsi } \\
\text { lindung dan fungsi budidaya (S2, S3) } \\
\text { 7. Mitigasi dan adaptasi perubahan lingkungan melalui pendekatan teknis } \\
\text { berupa pembangunan talud atau melalui pendekatan ekosistem berupa } \\
\text { penanaman mangrove (Pasal } 1 \text { ayat } 6 \text { PP No. } 21 \text { Tahun } 2018 \text { Tentang } \\
\text { Penyelenggaraan Penanggulangan Bencana (S4) }\end{array}$ \\
\hline $\mathrm{R}-\mathrm{I}$ & Control & $\begin{array}{l}\text { 8. Penanganan masalah pencemaran perairan melalui pembersihan pantai } \\
\text { secara berkala, penyediaan bank sampah, penertiban saluran buangan } \\
\text { limbah dan mengontrol pembuangan limbah (I1) } \\
\text { 9. Sanksi hukum melanggar batas wilayah penggunaan lahan sebagai } \\
\text { penertiban (UU NO 26 Tahun 2007) (I2) } \\
\text { 10. Melakukan evaluasi Analisis Mengenai Dampak Lingkungan (AMDAL) } \\
\text { secara rutin untuk mengetahui pelanggaran lingkungan yang dilakukan (I3) } \\
\text { 11. Silvovishery dan pembentukan kelompok budidaya (Amrial, dkk., 2015; } \\
\text { Hermawan, } d k k ., \text { 2017) (I4,I5) }\end{array}$ \\
\hline
\end{tabular}




\section{KESIMPULAN DAN SARAN}

Bersasarkan uraian hasil dan pembahasan maka dapat disimpulkan sebagai berikut:

1. Potensi ruang sub-zona budidaya di Teluk Kotania dengan luas 361,69 ha memiliki nilai kesesuaian budidaya laut sangat baik untuk pengembangan budidaya rumput laut, teripang, kepiting bakau dan ikan kerapu.

2. Terdapat 11 strategi pengelolaan yang dapat direkomendasikan untuk kegiatan budidaya laut di Teluk Kotania.

Berdasarkan penelitian ini maka dapat disarankan untuk melakukan kegiatan evaluasi dan monitoring terhadap implementasi hasil kesesuaian lahan budidaya laut dan dampaknya terdahap kesejahteraan masyarakat.

\section{DAFTAR PUSTAKA}

Adipu, Y., C. Lumenta, E. Kaligis, H. J. Sinjal. Kesesuaian Lahan Budidaya Laut di Perairan Bolaang Mangondow Selatan, Sulawesi Utara. Jurnal Perikanan dan Kelautan Tropis IX(1): 19-26.

Amrial, Y., H. Effendi, A. Damar. 2015. Pengelolaan Ekosistem Mangrove Berbasis Silvofishery di Kecamatan Cibuaya, Kabupaten Karawang. Jurnal Kebijakan Sosek KP 5(1): 59-70.

Arthatiani, F. Y., E. S. Luhur, A. Zulham, J. Haryadi. 2014. Peluang Optimalisasi Pengembangan Budidaya Kepiting Soka di Wilayah Kimbis Cakradonya Kota Banda Aceh. Jurnal Kebijakan Sosek KP 4(2): 137146.

Ariyati, R.W., L. Syah'rani, dan E. Arini. 2007. Analisis Kesesuaian Perairan Pulau Karimunjawa dan Pulau Kemujan sebagai Lahan Budidaya Rumput Laut Menggunakan Sistim Informasi Geografis. Jurnal Pasir Laut. 3(1): 27-45.

Astuti, I.R. \& F. Ariestyani. 2013. Potensi dan Prospek Ekonomis Udang Mantis di Indonesia. Media Akuakultur 8(1): 39-44. DOI: http://dx.doi.org/10.15578/ma.8.1.2013. 39-44.

Hasnawi, A. Mustafa, M. Paena. 2011. Evaluasi Kesesuaian Lahan Untuk Budidaya Ikan Dalam Keramba Jaring Apung Di Perairan Pesisir Kabupaten Mamuju Provinsi Sulawesi Barat. Jurnal Riset Akuakultur 6(1): 157-167. DOI: http://dx.doi.org/10.15578/jra.6.1.2011.1 $57-167$.
Hermawan, A., S. Amanah, A. Fatchiya. 2017. Partisipasi Pembudidaya Ikan Dalam Kelompok Usaha Akuakultur di Kabupaten Tasikmalaya, Jawa Barat. Jurnal Penyuluhan 13(1): 1-13.

Huliselan N.V., M. Wawo, M.A. Tuapattinaja, D Sahetapy, 2017. Present Status of Grouper Fisheries at Waters of Kotania Bay, Western Seram District Maluku Province. IOP Conference Series: Earth and Environmental Science 89 (2017) 012002 doi:10.1088/17551315/89/1/ 012002.

Huliselan N.V, M.Wawo, M.A. Tuapattinaja, D. Sahetapy, 2018. Keberlanjutan Pupulasi Ikan Dewasa Berdasarkan Kontribusi Larva untuk Meningkatkan Ekonomi Nelayan Seram Barat, Provinsi Maluku Laporan Akhir Penelitian Terapan, Direktorat Penelitian dan Pengembangan Masyarakat, Kementerian Riset, Teknologi dan Pendidikan Tinggi R.I : 149 hal.

Keputusan Menteri Negara Lingkungan Hidup Nomor 51 Tahun 2004 Tentang Baku Mutu Air Laut untuk Biota Laut.

Lesmana, D., R. Ratina dan Jumriani, 2011. Hubungan Persepsi dan Faktor Sosial Ekonomi Terhadap Keputusan Petani Mengembangan Pola Kemitraan Petani Plasma Mandiri Kelapa Sawit (Elaeis guineensis jacq.) di Kelurahan Bantuas Kecamatan Palaran Kota Samarinda. Jurnal EPP 8(2): 8-17.

Maesaroh, S., B. Barus, L. S. Iman. 2013. Analisis Pemanfaatan Ruang Wilayah Pesisir Kabupaten Pandeglang, Provinsi Banten. Jurnal Tanah Lingkungan 15(2): 45-51. ISSN 1410-7333.

Nanlohy, H. 2014. Partisipasi Masyarakat Pesisir Dalam Pengelolaan Kawasan Mangrove Di Teluk Kotania.. J. Fish. Sci XVI (2): 66-71 ISSN: 0853-6384. https://doi.org/10.22146/ jfs.9107.

Oedjoe, M.D. R., F. Rebhung, Sunadji. 2019. Rumput Laut (Kappaphycus alvarezii) ebagai Komoditas Unggulan dalam Meningkatkan Nilai Tambah bagi Kesejahteraan Masyarakat di Provinsi Nusa Tenggara Timur. Jurnal Ilmiah Perikanan dan Kelautan 11(1): 62-69. DOI=10.20473/jipk.v11i1.10992.

Rarung, L.K \& S. B. Pratasik. 2010. Potensi Jenisjenis Ikan Air Tawar Konsumsi Masyarakat Aliran Sungai Digoel, Kabupaten Boven Digoel, Papua, dan Beberapa Langkah Pengelolaannya. Jurnal Perikanan dan Kelautan VI(1): 41-45. 
Ratna \& A. M. Suruwaky. 2016. Analisa Kelayakan Usaha Budidaya Teripang (Holothuroidea) di Distrik Samate, Kabupaten Raja Ampat. Jurnal Airaha 5(1): 78-82. ISSN 2130-7163.

Setiawan F. \& Triyanto. 2012. Studi Kesesuaian Lahan untuk Pengembangan Silvofishery Kepiting Bakau (Scylla serrata) di Kabupaten Berau, Kalimantan Timur. Limnotek 19(2): 158-165.

Setyono, D. E. D. 2004. Pengetahuan Dasar Akuakultur. Oseana XXIX(1): 27-32.

Shafitri N. \& P. A. Soejarwo. 2017. Potensi dan Peluang Pengembangan Perikanan Budidaya di Kabupaten Kepulauan Anambas. Jurnal Kebijakan Sosek KP 7(2): 143-157.

Soejarwo, P. A. \& W. P. Fitriyanny. 2016. Pengelolaan Budidaya Rumput Laut Berkelanjutan untuk Masyarakat Pesisir Pulau
DOI: https://doi.org/10.30598/TRITONvol16issue1page28-37

Panjang Serang, Banten. Jurnal Kebijakan Sosek KP 6(2): 123-134.

Suban, F., I. R. N. Salindeho, N. P. L. Pengemanan. 2019. Kajian Daya Dukung Perairan danau Tutud, Tombatu, Minahasa Tenggara, untuk Akuakultur Dengan Parameter Fosfor (P). Jurnal Ilmiah Platax 7(2): 369-382. ISSN 2302-3589.

Sulardiono, B., P. W. Purnomo, Haeruddin. 2017. Tingkat Kesesuaian Lingkungan Perairan Habitat Teripang (Echinodermata : Holothuroidea) di Karimun Jawa. Saintek Perikanan 12(2): 93-97.

Worang, B. C.G.S., H. J. Sinjal, R. D. Monijung. 2018. Strategi Pengembangan Budidaya Perikanan Air Tawar di Kecamatan Dimembe Kabupaten Minahasa Utara Provinsi Sulawesi Utara. Budidaya Perairan 6(2): 68-76. 